employed in approximately 2627 public and 321 private hospitals in Thailand.

Methods The cross-sectional study aimed to investigate the occupational health and safety management in five Thai hospitals. The questionnaire consisted of characteristic of healthcare workers both working directly with patient such as inpatient, out- patient and not working directly with patients such as nutrition service and hospital supporting service departments, accident statistics and occupational health and safety management.

Results The result showed that healthcare workers in inpatient department had highest percentage reporting all 29 items of occupational health and safety management such as having safety policy, communication of policy to staff, having safety committee meeting, alarm system preparedness, fire prevention and protection preparedness, personal protective equipment provided, etc. followed by out-patient, nutrition service and hospital supporting service departments. The accident in the past three months indicated that the accident of sharp injury and falling from slippery floor in the nutrition service were $57.7 \%$ and $26.9 \%$, respectively. Furthermore, the comparison of the accident of sharp injury and falling from slippery floor of nutrition service with other departments was statistically significant different $(\mathrm{p}<0.001)$. The accident of needle stick and contact with chemicals, body fluid in surgery and anaesthesia department were $26.9 \%$ and $11.5 \%$, respectively. The comparison of needle stick and contact with chemicals, body fluid of surgery and anaesthesia department with other departments was statistically significant different that were $\mathrm{p}<0.001$ and $\mathrm{p}=0.024$, respectively.

Conclusion The situations of occupational health and safety management in Thai hospital were crucial for problem recognition and making the further control measure

\section{OCCUPATIONAL STRESS AND DEPRESSIVE SYMPTOMS IN HOSPITAL DOCTORS WORKING IN IRELAND}

${ }^{1}$ Anthony O' Keeffe*, Blánaid Hayes ${ }^{1},{ }^{2}$ Lucia Prihodova. ${ }^{1}$ Faculty of Occupational Medicine, $R C P I$, Dublin, Ireland; ${ }^{2}$ Research department, RCPI, Dublin, Ireland

\subsection{6/oemed-2018-ICOHabstracts.968}

Background Depression is reported to be prevalent amongst doctors and can have serious implications on the individual and on patient care. Previous studies have demonstrated an association between occupational stress (OS) and depressive symptoms amongst doctors. This study assessed the association between OS and depressive symptoms in hospital doctors in Ireland.

Methods In this randomised cross-sectional survey, 1749 doctors (950 consultants, 799 trainees) provided data on demographics (age, sex) and work (specialty, grade, working hours). Effort Reward Imbalance questionnaire was used to assess OS (effort-reward ratio [ERR], overcommitment [OC]). The WHO-5 Wellbeing index was used to assess depressive symptoms (two categories: 'normal/mild' vs 'likely depression'). Chi-square tests and t-tests were used to test differences in depressive symptoms and OS for sex, work grade and specialty. Binary logistic regression was performed to determine the association between OS and depressive symptoms, while controlling for sex, age, grade, specialty and mean hours worked.
Results Compared to males, females reported higher mean ERR and OC. Trainees reported higher mean ERR, OC and higher prevalence of 'likely depression' compared with consultants $(27.4 \%-\mathrm{v}-17.8 \%, \mathrm{p}=0.000)$. Those in the upper ERR tertile were more likely to experience depressive symptoms than those in the lowe tertile $(\mathrm{OR}=3.723$; CI: 2.634 to $5.263 ; \mathrm{p}=0.000)$. Those in the upper OC tertile were significantly more likely to experience depressive symptoms than those in the lowest tertile $(\mathrm{OR}=4.003$; CI: 2.87 to 5.884; $\mathrm{p}=0.000)$. Mean hours worked $(\mathrm{OR}=1.02 ; \mathrm{CI} ; 1.009$ to 1.03 ; $\mathrm{p}=0.000$ ) and grade (consultants $[\mathrm{OR}=0.496 ; \mathrm{CI}: 0.292$ to $0.843 ; \mathrm{p}=0.01]$ ) were significantly associated with depressive symptoms, whereas age, sex and specialty were not. The model explained $18 \%$ of variance.

Discussion OS and work conditions are associated with depressive symptoms in hospital doctors in Ireland. Efforts to reduce OS, such as review of work conditions or occupational social support, should be undertaken to improve psychological wellbeing.

\section{A SAMPLE TO DETERMINE THE CONDITIONS AND PROBLEMS FACED BY DISABLED HEALTH CARE PROFESSIONALS: A TRAINING AND RESEARCH HOSPITAL}

M Picakciefe, V Akkaya, E Erbas. Department of Public Health, Faculty of Medicine, Mugla Sitki Kocman University, Mugla, Turkey

\subsection{6/oemed-2018-ICOHabstracts.969}

Introduction It is predicted that worldwide, there are over one billion people who live with one sort of disability or another. The objective of this study was to determine the conditions and the problems faced by disabled health care professionals working in a training and research hospital.

Methods The method is a cross-sectional and definitive study. The population of study was comprised of 908 health care workers in a training and research hospital in Mugla, Turkey. A list was obtained from the human resources department of the hospital management and 323 people (accessibility rate $35.5 \%$ ) agreed to participate in a survey to determine disability. A brief set of questions prepared by the Washington Disability Statistics Group was implemented. The set results defined 63 people as being disabled (19.5\%).

Result The findings indicated that among the disabled health care workers, $44.5 \%$ were older (above the age of 40 ), $65.5 \%$ were females, $60.3 \%$ had a educational status of university or less, $38.1 \%$ were doctors, and $52.4 \%$ worked in the clinical sciences. $13.0 \%$ of the health care workers had cognitive impairment. $15.9 \%$ suffered from cardiac or circulatory ailments, $85.7 \%$ had complained of fatigue, and $73.0 \%$ had muscular-joint pains. In addition, $77.8 \%$ of the health care workers indicated that they had difficulties in commutes to and from the hospital in terms of the routes and the means of transport available. $65.1 \%$ claimed they found the breaks to be insufficient, $58.7 \%$ said they were victims of mobbing, $57.1 \%$ stated they desired to work part-time, and $55.6 \%$ indicated they worked in positions which did not necessitate any skill sets.

Discussion It appears disabled health care professionals face a number of negativities. A common set of definitions and a disability detection form should be established and prepared in 
order to enable the possibility of comparing results on an international basis.

\section{PREVALENCE AND RISK FACTORS FOR HAND ECZEMA AMONG NORWEGIAN SPECIALIST NURSES: A CROSS- SECTIONAL STUDY}

${ }^{1} \mathrm{LC}$ Resch* ${ }^{1}$ I Sandven, ${ }^{2} \mathrm{P}$ Brenno, ${ }^{2} \mathrm{~T}$ Bakkerud, ${ }^{3} \mathrm{TE}$ Danielsen, ${ }^{4} \mathrm{JH}$ Alfonso. ${ }^{1} \mathrm{Dep}$. of Occupational and Environmental Medicine. Oslo University Hospital, Oslo, Norway; ${ }^{2}$ Occupational Health Service. Oslo University Hospital, Oslo, Norway; ${ }^{3}$ Norwegian Labour Inspectorate, Trondheim, Norway; ${ }^{4}$ Depatment of Occupational Medicine and Epidemiology, National Institute of Occupational Health, Oslo. Norway

\subsection{6/oemed-2018-ICOHabstracts.970}

Background Hand eczema (HE), the most frequent workrelated skin disease, is common among health workers, but knowledge about its occurrence in Norwegian specialist nurses is scarce.

We aimed to investigate the prevalence of hand eczema and identify occupational and non-occupational risk factors among specialist nurses working at the Oslo University Hospital.

Methods A cross-sectional survey of 115 specialist nurses (surgical and anestesics) was performed by using an adapted version of the Nordic Occupational Skin Questionnaire (NOSQ 2002-Norwegian), which includes standardised questions for $\mathrm{HE}$, occupational and non-occupational exposures. Analyses comprised descriptive statistics and logistic regression (STATA 14).

Results The participation frequency was 99.1\%. Nearly threequarters of the participants reported skin symptoms during the last 12 months. The lifetime prevalence, one-year prevalence and point prevalence of $\mathrm{HE}$ was $27.19 \%, 17.54 \%$, and $11.40 \%$; the prevalence of work-related $\mathrm{HE}$ was $14.9 \%$. Although HE was more common in women, we did not find an association between sex and HE. Age, childhood eczema, and amount of years working as a specialist nurse were consistent predictors for work-related HE. Time spent using protective gloves did not predict work-related $\mathrm{HE}$, but selfreported skin symptoms when using protective gloves was a consistent predictor. The most common aggravating factors at work comprised hand cleaning and disinfection, water and winter season. Domestic exposures (food preparation, cleaning/ washing, care for children under 4 years, contact with animals) did not predict either HE or work-related HE.

Conclusion The one-year prevalence for $\mathrm{HE}$ was almost twice, and for work-related HE was nearly thrice than in the general population. The occurrence of work-related HE was associated with older age, childhood eczema, amount of years working as specialist nurse, and skin symptoms when wearing protective gloves. A potential healthy worker survivor effect may underestimate the prevalence figures and associations reported here. Prevention strategies focusing on skin care and protection should be developed for specialist nurses.

\section{\begin{tabular}{|l|l}
\hline 405 & UPPER EXTREMITIES STRAIN ASSESSMENT IN NURSING
\end{tabular} PERSONNEL}

${ }^{1}$ Davor Romih*, 'Dani Mirnik, 'Marjan Bilban, ${ }^{2}$ Tihomir Ratkajec. 'Institute of Occupational Safety, Department of Occupational Health, Ljubljana, Slovenia; ${ }^{2}$ Medicina dela Rogaška, Rogaška Slatina, Slovenia

10.1136/oemed-2018-ICOHabstracts.971
Introduction Besides work-related low back pain, disorders of neck-shoulder-arm area have also become increasingly common amongst nursing personnel. Analysis of working postures according to OWAS method demonstrated that more than $25 \%$ of the working time the abduction of the upper limb was between 30 and 90 degrees. At that point ergonomic measures should be considered. This study was conducted to determine whether different bed positions effect deltoid muscle activity during nursing tasks.

Methods Seven nurses in a geriatric nursing home participated in the study. Surface electromyography was used to assess local strain of the deltoid muscle during standardised morning care routine of immobile patients. Each participant conducted measurements with four different bed conditions: 1. recommended bed height according to the anthropometric characteristics with side rails up; 2. recommended height with side rails down; 3. recommended height lowered by 10 centimetres with side rails up; 4. lowered height with side rails down. Statistical analysis was performed on the basis of non-parametric Wilcoxon matched pairs test. The value $\mathrm{p}<0.05$ was considered to be statistically significant.

Result There were no statistically significant differences between all four cases. Deltoid muscle activity was neither influenced by the height of the bed $(p=0.078-1.00)$ nor by the positions of the side rails $(p=0,047-0.33)$.

Discussion Differences in bed height or the position of the side rails did not result in significant change of deltoid muscles activity. Therefore, further ergonomic evaluations need to be considered to determine the true origin of shoulder discomfort and why upper limb postures are above critical ergonomic values amongst nursing personnel.

\section{FEASIBILITY AND ACCEPTABILITY OF A WORK-BASED COLORECTAL CANCER SCREENING INITIATIVE IN FLORIDA FIREFIGHTERS}

\footnotetext{
${ }^{1,2}$ Natasha Schaefer Solle ${ }^{*},{ }^{1,2}$ Daniel Sussman, ${ }^{2,3}$ Alberto I Caban-Martinez, ${ }^{1,3}$ Colette Tse, ${ }^{1,3}$ Jennifer Tibangin, ${ }^{2,3}$ David I Lee, ${ }^{1,2}$ Erin N Kobetz. ${ }^{1}$ Department of Medicine, University of Miami, Miller School of Medicine, Miami, FL, USA; ${ }^{2}$ Sylvester Comprehensive Cancer Centre, University of Miami, Miami, FL, USA; ${ }^{3}$ Department of Public Health Sciences, University of Miami, Miller School of Medicine, Miami, FL, USA
}

10.1136/oemed-2018-ICOHabstracts.972

Introduction Colorectal cancer (CRC) has been identified as one of the top diagnosed cancers among firefighters in Florida, United States. Firefighters are routinely exposed to highly toxic materials, many of which have been linked to an increased risk for colorectal cancer. Despite the elevated risk, cancer screening behaviours of active firefighters are unknown. We assessed the feasibility, acceptability, and implementation of a worksite-based cancer screening program using faecal immunochemical testing (FIT) among unscreened and underscreened Florida firefighters.

Methods In collaboration with Florida fire departments, participants were recruited through their fire department. All participants completed an eligibility screener, informed consent and demographic questionnaire. Firefighters subsequently received a FIT kit in-person or via mail and returned specimens to the lab for testing. Screening results were reported to participants via telephone and those who screened positive were referred for colonoscopy.

Result Collectively, 1611 firefighters were screened for eligibility of whom $525(32.6 \%)$ were eligible. Ineligible firefighters 